\title{
Cavaleiros em Tempos de Glória: uma análise etnográfica da história do vaqueiro do Nordeste
}

\author{
RENAN MARTINS PEREIRA
}

\section{Introdução}

Em fevereiro de 2016, para a elaboração da minha dissertação de mestrado, iniciei uma pesquisa de campo no município de Floresta ${ }^{1}$, sertão de Itaparica, Pernambuco, que resultou em uma etnografia sobre os vaqueiros do município, com foco nas suas relações com a memória e os animais (Pereira 2017). Nesse trabalho, pretendi analisar como os habitantes do município, no que se refere ao tema do vaqueiro sertanejo e sua história ${ }^{2}$, deparam-se frequentemente com um dilema.

Em Floresta, ninguém diz: 'O vaqueiro não existe mais’’3. Uma afirmação como essa não me foi dita em momento algum. Pelo contrário, quando se recorre a alguém e lhe faz qualquer pergunta sobre o tema, de imediato se afirma que 'Floresta é a capital do vaqueiro'. O curioso é que, simultaneamente a isso, pode surgir da boca de alguém a seguinte expressão: 'O vaqueiro está desaparecendo' ou 'O vaqueiro desaparecerá.

Segundo meus interlocutores, o que os levam a se interrogar a respeito da existência do vaqueiro ou de sua suposta desaparição futura é que, hoje em dia, são raros os homens que se dedicam ao $c a m p o^{4}$,

1 Floresta está localizada na mesorregião do São Francisco e na microrregião do Sertão de Itaparica, distante 439 km da capital do estado, Recife. Segundo dados do IBGE/2016, sua população estimada é de 32.152 habitantes.

2 A partir de eixos analíticos e temáticas específicas, poucas etnografias têm sido produzidas nos últimos anos a respeito do vaqueiro sertanejo, por exemplo: Aires (2008) e Lopes (2016).

3 Termos em itálico correspondem a expressões nativas. Frases entre aspas simples representam transcrições diretas da fala nativa e frases entre aspas duplas representam citações de autores acompanhadas de referência bibliográfica.

4 Campo significa a parte não cercada da caatinga. É o território onde nasce e vive o rebanho 'criado solto no mato', que em certos períodos necessita ser recrutado para fins de manutenção e vigília de vaqueiros e criadores. A forma verbal campear é, no que se refere às atividades do vaqueiro, sinônimo de procurar, capturar e dominar na espacialidade do campo os animais selvagens. Criadores são, de modo geral, quaisquer pessoas que criam gado caprino, ovino, bovino ou equino. Mas criador se distingue de vaqueiro: sujeito hábil na arte de capturar os animais indomáveis. Entre os animais, as diferenças básicas consistem em quatro termos convencionais: criação (rebanho de caprinos e ovinos), criatório de gado (refere-se apenas ao gado bovino), animal (sempre o gado equino) e criatório (totalidade do rebanho de todas as espécies). 
cuidando do rebanho próprio ou do patrão e, sobretudo, hábeis na arte de capturar as reses selvagens na caatinga. As razões, para tanto, segundo eles, é que as secas ${ }^{5}$, os cercados e as subsequentes mudanças na natureza dos animais e no ambiente têm levado o sertão a uma nova modulação ecológica na qual, dizem, não é possível ser vaqueiro como no tempo dos antigos.

Apesar disso, há os que se dizem e se consideram vaqueiros sem, no entanto, serem reconhecidos como vaqueiros de verdade. É o caso, por exemplo, de vaqueiros de vaquejada, vaqueiros de pega de boi ${ }^{6}$, vaqueiros de festa, assim como crianças, jovens e adultos que vestem a indumentária de couro apenas para desfilar em missas e cavalarias ou para correr em vaquejadas. Mobilizando a memória para se posicionarem no presente, dizem: 'Essa é a nossa tradição' 'Meu pai e meu avô foram vaqueiros.' 'Eu não trabalho no campo, mas tenho sangue de vaqueiro.?

Diante disso, o objetivo principal deste artigo é analisar o que é historicamente o vaqueiro sertanejo para a literatura nacional (que denominarei de saber oficial) e para os saberes de meus interlocutores (que denominarei de saber local) ${ }^{8}$, a fim de entender como cada um desses saberes constroem uma estabilização imagética e conceitual do passado que se concretiza, neste caso, na figura do vaqueiro de verdade, original e autêntico. Minha hipótese nesse sentido é que o vaqueiro sertanejo não é uma mera resistência histórica, coberta de regionalismos e tradicionalismos, como sustentam, por exemplo, as célebres teses sobre o Nordeste brasileiro (Barroso 1956 [1912]; Menezes 1970 [1937]; Andrade 1986 [1963]; Cascudo 1956 e 2005 [1939]; Prado Junior 2006 [1945]; Furtado 2007 [1959]; Mello 2011 [1985]). Em contrapartida, sugiro que ser vaqueiro, tal como os meus interlocutores a entendem, é uma posição disputada, em constante transformação e que se expressa de maneira simultaneamente histórica e contemporânea.

Na primeira seção, o objetivo é analisar o que significa para o saber local e o saber oficial a verdade histórica do vaqueiro sertanejo. Na segunda seção, procuro analisar a partir de um acontecimento etnográfico específico o estatuto do passado na construção e na definição da originalidade e da autenticidade do vaqueiro de verdade. Na terceira seção, analisarei como a verdade histórica do vaqueiro se

5 Categoria em destaque, via de regra, pela sua complexidade histórica, pelos quase um século e meio de intervenção estatal em vias de combater e mitigar as secas na região semiárida do Nordeste, pelos diferentes significados que recebe (tanto pelas populações locais quanto pela literatura nacional), e, ainda, podemos dizer, pelas diversas possibilidades de entendê-la e classificá-la desde as relações dos sertanejos com a terra, a memória, o tempo, as águas e os animais - as quais não são o objetivo deste artigo, mas que receberão um debate mais aprofundado, no que se refere à questão das secas, na última seção.

6 O termo pega de boi corresponde à prática tradicional do vaqueiro de derrubar o gado na caatinga em velocidade para fins de manutenção e vigília do rebanho. Desta prática de trabalho foi derivada uma outra, a pega de boi no mato. Também chamada contemporaneamente de vaquejada, a pega de boi no mato ou pega de boi na caatinga é uma competição em que um conjunto de vaqueiros, a vaqueirama, corre à procura do gado para derrubá-lo e capturá-lo, visando o festejo, a comemoração e a premiação.

7 Quanto à correlação temática entre sangue e memória, não é minha pretensão desenvolver neste artigo uma análise da relação entre esses dois importantes temas antropológicos (Carsten 2013). Temas que, inclusive, são objetos de investigação de Marques (2013) e Marques e Villela (2016) no sertão de Pernambuco, além de tema central para Sanjurjo (2013) em sua etnografia sobre o passado ditatorial argentino.

8 Não proponho uma adesão à hermenêutica de Geertz para tratar de pontos de vista e descrições nativas, tais como no sentido conferido por ele a partir das noções por exemplo de "descrição densa" (1978) e "saber local" (1997 [1983]). Aqui, para a definição do que chamo de saber local inspiro-me nas ideias de "saberes localizados" de Haraway (1995 [1988]) e de "etnografias do particular" de Abu -Lughod (1991). Em resumo, o que as duas autoras defendem é que falar do "outro" é produzir narrativas acerca de nossa familiarização com ele. É preciso registrar particularizações, em vez de diferenciações entre sujeito e objeto. É preciso deixar de produzir generalizações que distanciem e isolem os "outros" de nós mesmos. Considerar o "particular”, segundo Abu-Lughod (1991), é não recorrer à homogeneidade, à coerência e à atemporalidade. 
fundamenta na noção de tradição constantemente mobilizada pelos meus interlocutores de pesquisa. $\mathrm{Na}$ quarta seção, trabalharei analiticamente as relações históricas entre vaqueiros e fazendeiros. E, na quinta e última seção, analisarei como as relações ecológicas com os animais e as caatingas se transformaram ao longo do tempo em virtude das secas e dos cercados, resultando em uma imediata transformação na vida de vaqueiro. Por fim, concluo que a história do vaqueiro do Nordeste só pode ser entendida etnograficamente a partir de estratégias contemporâneas de reconstrução dos acontecimentos, através principalmente da memória e da habilidade retórica de meus interlocutores de conferirem verdade ao que viveram.

\section{Verdade histórica}

Segundo a literatura nacional (Cascudo 2005 [1939], 1956; Menezes 1970 [1937]; Mello 2011 [1985]), o modelo pastoril do Nordeste deu origem à particularidade da sociedade sertaneja. Os objetivos do saber oficial foram os de compreender os significados de certas tipologias humanas conectadas a uma totalidade social, ao meio natural e aos valores morais, todos eles influentes na constituição das subjetividades, das morfologias físicas e dos costumes. A defesa de seus autores por uma totalidade parece depender de um método comparativo capaz de dar dimensões classificatórias, a partir das quais se chegaria à singularidade histórica da pecuária nordestina e do "perfil psicológico-social do homem pecuário do Nordeste" (Mello 2011 [1985]: 47).

Segundo o saber oficial, é fundamental para se compreender a sociedade sertaneja - ou o "Outro Nordeste”, tal como formulado por Menezes (1970 [1937]) - que o seu sistema econômico seja contrastado com o que lhe antecedeu e o originou: o "ciclo da cana-de-açúcar", como denomina Mello (2011 [1985]: 42-43). Comparar, assemelhar e diferenciar o sistema das lavouras e dos engenhos com o pastoreio seria, para alguns pensadores, um modo de classificar dois modelos econômicos fundantes de uma única sociabilidade histórica. Tal abordagem divide em duas vertentes a economia colonial. Como um "jogo de estereótipos”, nas palavras de Herzfeld (2008 [1997]), essa abordagem estabiliza dois processos históricos que, segundo Cascudo, são dois “dois tipos de cultura" (1956: 27-28) contínuos, complementares e, por vezes, a imagem reversa um do outro.

De um lado, tem-se a produção açucareira do litoral, definida a partir de prerrogativas como o coletivismo das relações sociais, o trabalho escravo, a exportação de monocultura e o seu contato permanente com o Velho Mundo. De outro lado, resultante do primeiro tipo, tem-se o modelo pastoril dos sertões, ao qual é creditado, por exemplo, o individualismo das relações sociais.

No litoral, segundo a literatura, o poder político era centralizado e os trabalhadores se identificavam como grupos. No pastoreio, em contrapartida, as relações políticas eram mais fluidas e dispersas, e as pessoas estavam à sorte de suas próprias leis e geograficamente isoladas (Mello 2011 [1985]: 51). Disso resultam outras de suas características, a saber: o trabalho livre executado pela mão-de-obra nativa (mantida pelo absenteísmo de fazendeiros e boiadeiros que delegavam a seus vaqueiros o poder sobre a propriedade) e a função de abastecer o litoral com a carne do gado (portanto, economia não -exportadora). 
No entanto, a polarização entre "dois tipos de cultura" parece se esgotar em si mesma como justificativa sociológica, uma vez que só serviu, em grande medida, para definir tipos sociais, geográficos e humanos encerrados em meras abstrações analíticas. Se olharmos detidamente para o que disse Cascudo (1956) acerca da “indústria açucareira”, podemos imediatamente verificar a seguinte conclusão:

Desta indústria, que é fórmula de aglutinação coletivista, o canto será sempre uníssono e coral, a mentalidade surge condicionada aos interesses imediatos do grupo humano a que pertence o trabalhador. O ciclo da cana-de-açúcar não pode produzir o cangaceiro, o cantador de pandeiro e de viola, o improvisador, o dançarino solista, o artesão independente, o cavalariano afoito, o beato aliciante, o jagunço, o fanático (Cascudo 1956: 27).

Com sua tática polarizadora e comparativa, o saber oficial notou aliás que a pecuária nordestina produziu diversas singularidades inexistente nas lavouras e nos engenhos, entre elas o poder dado aos vaqueiros pelos seus patrões. Fazendeiros e boiadeiros faziam com que seus vaqueiros, ao tomar conta das terras e dos rebanhos, obtivessem maior prestígio se comparado ao de outros trabalhadores (como, por exemplo, almocreves, tangerinos, moradores, meeiros, lavradores, agricultores), e mesmo ao de outros vaqueiros que não eram os responsáveis diretos pela propriedade e pelo rebanho bovino selvagem, mas sim pelos rebanhos de bode, pelo gado leiteiro (domesticado e cercado) ou pelos animais de carga.

Percebe-se, portanto, que o vaqueiro que tinha poder sobre os trabalhadores e cuidava do rebanho selvagem ganhava maior notoriedade e prestígio que os demais no contexto da economia pastoril. Ou seja, alguns recebiam o poder de comandar o conjunto de trabalhadores de uma propriedade, e outros se tornavam conhecidos, segundo meus próprios interlocutores, por terem sido corajosos, valentes ou bons vaqueiros ao se destacarem na lida com o gado na caatinga. ${ }^{9}$

$\mathrm{Na}$ chave das relações de trabalho entre vaqueiros e fazendeiros, as análises de Medrado (2012) sobre o sertão da Bahia se assemelham com as minhas, no sentido de que, no sertão de Pernambuco, o prestígio dos vaqueiros resulta também, tal como na região analisada pela autora, de dois contextos: (1) das relações de cumplicidade e confiança entre vaqueiros e fazendeiros e (2) das relações dos vaqueiros com o gado (2012: 157-158).

Curiosamente, a esse respeito Cascudo (1956) formulou uma outra imagem, desta vez focalizada nitidamente na figura do vaqueiro, dando-nos o contorno romantizado de um personagem histórico único:

O ciclo do gado determina o individualismo do seu participante. Dá-lhe a noção imediata de independência, de improvisação, de autonomia, de livre arbítrio, de arrojo pessoal. Fundada a fazenda, o vaqueiro antigamente um escravo, ficava senhor do gado, da casa, dos cavalos, responsável pelas iniciativas imediatas para defender os animais entregues à sua energia. Movimenta-se livremente

9 No sertão de Pernambuco, a lida se refere à relação diária e ao trabalho cotidiano com o gado bovino. Para o conjunto de atividades relacionadas à manutenção do rebanho, diz-se: lida do gado. De forma substantiva (lida) e poucas vezes em sua forma verbal lidar, ela se refere, portanto, à conformação de uma série de atividades da fazenda, de empreendimentos voltados à manutenção do rebanho, mas também ao ato de zelar a propriedade, sua vegetação, seus cercados, seus recursos hídricos, as moradas, etc. A isso tudo, então, dá-se o nome de lida da fazenda. Portanto, lida e lidar (sua forma verbal que às vezes irá aparecer aqui) significam, de um modo geral, um tipo de relação. De um lado, relações possíveis de serem travadas com o gado bovino (na lida do gado ou na lida com o gado), e, de outro, relações travadas no contexto da vida no campo (o complexo geral ao qual a lida da fazenda faz parte). 
nos plainos dos tabuleiros e caatingas, no galope árduo do seu cavalo de fábrica, caçando as reses tresmalhadas ou ariscas (Cascudo 1956: 27).

Interessante é que, não só da perspectiva do autor, mas também da de meus interlocutores, foi exatamente por meio das relações livres, épicas e aventurosas dos vaqueiros com os animais na caatinga que uns se destacavam mais que outros na lida com o gado bravio. Obedecendo a estrita função de vendê -lo a pedidos do patrão, os vaqueiros de verdade, segundo me diziam, eram homens do campo que sabiam as técnicas de capturá-lo e apartá-lo ${ }^{10}$, tornando-se renomados e afamados por serem habilidosos em sua empreitada. Portanto, é dessa demonstração de técnica e de agilidade que, no tempo dos antigos, alguns homens eram mais prestigiados, mais vaqueiros e, não menos, mais corajosos do que outros.

É importante recorrer a esse tipo de caracterização histórica, pois os vaqueiros desta pesquisa, como veremos ao longo deste artigo, também acionam caracterizações e generalizações bastante parecidas com as de Cascudo. Quando conversava com alguns vaqueiros de verdade em Floresta, estes recorriam em suas narrativas a certas artimanhas para se diferenciarem, na posição de antigos vaqueiros ou vaqueiros velhos, dos vaqueiros mais novos, vaqueirinhos ou vaqueiros modernos. ${ }^{11}$ Dentro desse contexto, de maneira geral é dado maior notoriedade e prestígio aos vaqueiros que diziam ter vivido no tempo em que fora possível criar 'gado brabo solto na caatinga', em campos indivisos, partilhados por homens e animais, na época em que os vaqueiros não conheciam, como quer Cascudo, a "imagem do limite" (1956: 13), mais ainda, no tempo em que era possível que o patrão confiasse no vaqueiro e este nos trabalhadores que compunham a mão-de obra humana da fazenda. Para melhor entender o estatuto do passado na definição de vaqueiro de verdade, trarei em seguida um acontecimento etnográfico.

\section{Original e autêntico}

Em Floresta, quando a palavra "vaqueiro" é evocada dá-se a ela um contexto preciso: a vida de vaqueiro no campo. No entanto, quando se procura por esse vaqueiro vivendo e labutando no campo, muitas vezes se ouve o seguinte questionamento: 'Mas será que isso ainda existe?.

Dois interlocutores, Quirino e Nilda, sugeriram a mim visitar uma determinada propriedade, a Fazenda Mãe d’Água, bastante conhecida em Floresta. Eles sabiam que lá havia vaqueiros trabalhando com o gado na produção de queijo (inclusive, 'a maior produtora de Floresta e também o melhor queijo', segundo eles), mas seria improvável encontrar vaqueiros na lida com o gado brabo. Embora tenham sugerido a mim que seria de grande valia conhecê-la, alertaram-me que na Fazenda Mãe d’Água eu poderia verificar uma outra perspectiva. Mas não exatamente a perspectiva do vaqueiro do campo.

Para Nilda e Quirino, a vontade de realizar uma pesquisa sobre o vaqueiro trabalhando diariamente na lida com o gado dificultavam os meus objetivos. O próprio advérbio de tempo "ainda" na pergunta do primeiro parágrafo desta seção demonstra que a vida de vaqueiro no campo parecia ser um modo de vida pretérito, por vezes pouco claro na percepção de muitos de meus interlocutores.

10 O ato de separar as reses de uma propriedade das propriedades vizinhas se chama "apartação" (Cascudo 2005 [1939]).

11 A maioria do material de campo que recolhi foram relatos, narrativas e conversas que estabeleci com vaqueiros antigos. Não recolhi material suficiente com vaqueiros mais novos ou vaqueiros de vaquejada que me permitisse contrastar analiticamente neste artigo as perspectivas destes com as daqueles. 
Sendo assim, interroguei-me: 'Se já me disseram que Floresta é a capital do vaqueiro, por que a dificuldade de encontrar uma fazenda onde ainda hoje existam homens trabalhando como vaqueiros? O que significa exatamente Floresta ser a capital do vaqueiro diante da própria dificuldade de encontrá-los aos arredores do município?'. Por conta disso, perguntei a Nilda e a Quirino se, por outro lado, nas pegas de boi no mato, outra modalidade em que o vaqueiro sertanejo se expressa, seria possível estabelecer alguns contatos relevantes de pesquisa, já que são práticas na de vida de muitos vaqueiros florestanos.

Os dois compreendiam que seria interessante pesquisar as pegas de boi no mato, os festejos e a sua dinâmica e muito provavelmente encontraria ali vaqueiros de verdade ou vaqueiros antigos. Mas, em contrapartida, o que acontece nas pegas de boi e nos festejos não é, segundo Nilda, autêntico e original. Ela inclusive chegou a dividir entre sagrado e profano, respectivamente, o antigo (o original e autêntico vaqueiro da lida) e o atual (por exemplo, o vaqueiro de festa), aliás, tentou compará-los de modo a estabilizar uma oposição, um contraste: 'A pega de boi é uma outra visão, uma outra perspectiva, uma outra dinâmica. Está mais vinculada à bebedeira e à mulherada. Eu acho que é mais interessante você ir atrás do vaqueiro autêntico, original, tradicional'.

Para Nilda e Quirino, quando se fala do vaqueiro sertanejo, trata-se, enfaticamente e em primeiro lugar, do vaqueiro, vaqueiro mesmo: o vaqueiro da lida e do campo. Nas palavras de Nilda, 'o sujeito autêntico e original do tempo de minha infância'. Desse sujeito histórico, Nilda não tinha atualmente muito conhecimento, mas ele próprio, enquanto imagem do passado, possibilitou-a resgatar de suas memórias algumas percepções e lembranças da época em que nas propriedades de suas famílias existiam vaqueiros lidando diretamente com o rebanho de gado bovino.

Minutos depois de nossa conversa, Nilda me dera a cópia de um capítulo de um livro chamado Tipos e Aspectos do Brasil, organizado pelo IBGE (Instituto Brasileiro de Geografia e Estatística), do qual ela tirara uma cópia do texto "Vaqueiro do Nordeste", sob a autoria da geógrafa Maria Fagundes de Souza Doca (IBGE 1956: 167-170). Estávamos sentados no sofá da entrada de sua casa e, em poucos minutos, ela começou a lê-lo por inteiro, linha por linha, almejando mostrar o que era o vaqueiro do ponto de vista de alguém que estudou o tema, uma 'especialista no assunto'. O pequeno artigo, além de conter uma representativa imagem, explicava o que seria de fato, segundo Nilda, o vaqueiro tradicional. $\mathrm{O}$ argumento geral do artigo é que a economia, a natureza e a cultura estão imbricadas conjuntamente como suporte analítico-descritivo do 'heroico e honesto tipo sertanejo' - como quer a geógrafa em seu texto.

Tanto neste artigo quanto nos argumentos do saber oficial, economia, natureza e cultura são fatores externos que condicionam os indivíduos a ações e a conhecimentos condizentes com uma realidade empírica previamente dada e que, sobre ela, resta aos indivíduos agirem conforme os resultados de suas relações com o ambiente, a partir de seus artifícios econômicos e culturais, isto é, a partir de condicionamentos flexionados pelas necessidades de subsistência do vaqueiro em um meio onde ora se luta contra as intempéries naturais, ora se reproduz os costumes das tradições e do cotidiano de trabalho.

Esse argumento que se pode ver nos livros e na retórica do saber oficial também está repercutido nas palavras dos mais renomados vaqueiros florestanos. $\mathrm{O}$ grande vaqueiro Antônio Balbino, por 
exemplo, apresentou no contexto de uma pega de boi no mato a sua perspectiva histórica a respeito dos vaqueiros de antigamente, os quais em sua fala estão refletidos como caboclo brabo, homi bruto ${ }^{12}$, um indio. Eis abaixo trecho de um diálogo que estabeleci com o interlocutor.

- Como é ser vaqueiro? - Suscitei a questão esperando que ele me dissesse de alguma forma o que significava para ele ser vaqueiro hoje em dia, e não, tal como ele apresentará a seguir de forma bastante curiosa, o que foi o vaqueiro há muito tempo atrás.

Ele respondeu:

- Os vaqueiros de antigamente eram uns homi bruto, um índio, um caboclo brabo, não sabe? Eles só aprenderam aquilo que aprenderam a fazer. Mas só aprenderam aquilo. $\mathrm{O}$ vaqueiro não sabia de nada, não tinha estudo de nada. Tinha deles que não sabia nem assinar a primeira letra do nome. Mas com a inteligência que Deus deu a ele, ele aprendeu tudo: pegar o boi, amarrar, seguir, tanger o boi bem direitinho, colocar no curral, dar de comer ao boi manso. Ele aprendeu tudo com aquilo que Deus lhe deu, pois ele não teve quem ensinasse a ele, o homi bruto.

Foi na vaqueja da Fazenda São Pedro que Antônio Balbino, logo após pegar um boi e botá-lo no curral, deu a mim sua breve análise. Interceptado por um de meus colegas, que sugeriu a ele que expusesse a mim algumas reflexões sobre o vaqueiro sertanejo, o que significa sê-lo e qual a diferença do vaqueiro de outrora para o de hoje, percebe-se que, ao fazê-lo, o vaqueiro apresentou, de saída, um exercício mnemônico composto por uma reflexão quase mítica, uma origem.

Enquanto conversávamos rapidamente, ainda em seu cavalo e afoito para correr e derrubar outra rês, Antônio não se disse mais vaqueiro ${ }^{13}$ do que os vaqueiros mais novos que estavam ao seu redor, embora pudesse contar mais histórias do que eles. Para os colegas que o arrodeavam, 'ele sim é considerado um vaqueiro de verdade!'. Ele tinha conhecimento da vida do campo e viveu no tempo em que para ser vaqueiro precisava-se de mais coragem do que hoje. Assim, foi conferido a ele, na sua relação com os demais, a posição de vaqueiro corajoso e catingueiro. ${ }^{14}$

Se a minha pesquisa era sobre o vaqueiro sertanejo, nada mais compreensível - do ponto de vista de meus interlocutores - que um grande vaqueiro (corajoso e catingueiro) fosse recrutado para que me desse a honra de suas palavras. Dos aproximadamente cento e cinquenta vaqueiros que estavam na vaquejada da Fazenda São Pedro, curioso foi o modo como me levaram primeiramente em direção a Antônio Balbino em detrimento de tantos outros vaqueiros que, naquele exato momento, compunham um grande coletivo, a vaqueirama. A justificativa para tanto é precisa: Antônio Balbino era um vaqueiro de verdade. Suas palavras não seriam quaisquer palavras, mas as palavras de um vaqueiro véio.

Se analisarmos as célebres teses do saber oficial até agora explicitadas, podemos perceber ressonâncias entre elas e a própria visão de Antônio Balbino. Em ambas, o vaqueiro nordestino aparece

12 Algumas palavras aparecerão sob o formato não convencional da ortografia portuguesa, dando destaque à sua importância estética na fala nativa, principalmente nas narrativas e nas histórias de vaqueiro.

13 Para uma reflexão do termo "vaqueiro" também sendo designado como adjetivo: cf. Medrado (2012: 127). No meu caso e no da autora, ser mais vaqueiro é quando um sujeito é melhor e mais verdadeiro do que outros, tendo como atributo diferencial a de ser um bom vaqueiro.

14 Catingueiro é o vaqueiro que tem maior domínio sobre o território e os animais, no contexto de suas carreiras (corridas a cavalo) atrás do gado. 
como um elemento aculturado resultante das políticas coloniais, do "contato do branco colonizador com o gentio, durante a penetração do gado nos sertões do Nordeste" - como consta no artigo apresentado por Nilda. O que se poder concluir até aqui é que tanto o saber oficial quanto as visões de Nilda e de Antônio Balbino dão pistas do que seja o vaqueiro original, autêntico e tradicional. As visões de meus interlocutores confluem com o saber oficial e com as imagens clássicas da literatura nacional sobre o vaqueiro nordestino.

No momento de minha conversa com Nilda, por exemplo, enquanto ela lia linha por linha daquele artigo, senti que pude dividir algumas de minhas reflexões com uma interlocutora que não conhecia muito bem a realidade de vida dos vaqueiros, como ela mesma afirmou várias vezes, mas que no entanto a respeito desse universo tinha algumas generalizações provenientes das reminiscências do tempo de sua infância, da fazenda de sua família e das leituras que fizera.

De um lado, um universo para mim totalmente desconhecido. Do outro, um universo recrutado por Nilda a partir da imagem que construiu para si mesma em torno de uma originalidade. Desde a prévia discussão entre dois desconhecedores daquele universo, percebi que ela e eu acabávamos por igualmente compartilhar pressuposições ancoradas na perspectiva de uma suposta tradição e cultura do vaqueiro. Eu compartilhava com ela, portanto, seus modos de reificar e essencializar elementos também generalizados pela literatura e pelo saber oficial.

Aliás, minha interlocutora exigia de mim, por assim dizer, a posição etnográfica - se quisermos - de um antropólogo culturalista, conforme a sua sugestão em privilegiar, como recorte analítico, sujeitos que se definem (e são definidos pelos outros) pela sua autenticidade. Por mais que eu pudesse discordar, na posição de antropólogo, de sua visão totalizante em perceber a cultura e a tradição como imperativos da realidade observada, o que estava sendo apresentado a mim, por outro lado, era a séria perspectiva de uma interlocutora refletindo a respeito das diferenças entre sujeitos e contextos sociais dados por ela como radicalmente díspares, embora às vezes confundidos uns com os outros, a saber: o vaqueiro da lida (no campo) e o vaqueiro de festa (nas vaquejadas).

A seguir, vejamos o que significa essa noção de tradição mobilizada constantemente pelos interlocutores de pesquisa.

\section{Vaqueiro simbólico e passado referencial}

A tradição sugere que a memória e o passado têm um estatuto importante na construção histórica do vaqueiro sertanejo tanto no discurso da literatura quanto no discurso nativo. Na literatura, a expansão da pecuária pelos sertões, como vimos na primeira seção, ganha maior centralidade analítica à medida que os autores produzem tipologias únicas de um passado mais remoto, o período colonial. $\mathrm{Na}$ memória de meus interlocutores, por sua vez, o retrospecto é menor. O tempo dos antigos não alcança o recorte temporal do Brasil colônia. No máximo, meus interlocutores flexionavam lembranças contextualizadas na primeira metade do século XX.

É válido destacar que a maioria dos vaqueiros velhos que conheci tinham entre 60 e 90 anos de idade. Quando falavam do tempo dos antigos, na maioria das vezes datavam os acontecimentos ocorri- 
dos depois dos anos de 1930 ou 40. Época em que, segundo diziam, a lida da fazenda estava moldada sob a configuração de poucos cercados, chuvas mais frequentes e com muito gado brabo. Ao mesmo tempo, também resgatavam histórias e comentários feitos por seus pais e avós, indo a um recorte temporal mais amplo e a um jogo de perspectivas capaz de introduzi-los em espacialidades e temporalidades que não viveram, mas sobre as quais poderiam discorrer abertamente.

Enfim, trata-se de uma imagem do vaqueiro nordestino que, em certas circunstâncias, representa o recorte temporal de cada um dos saberes. De um lado, a literatura e o saber oficial desenhando os sentidos do Estado-nação, de sua história e do seu desenvolvimento, e, de outro lado, os meus interlocutores e o saber local refletindo a respeito da tradição, cruzando-a por diversas vezes com o próprio discurso oficial. Nesse sentido, é importante notar nesses recortes temporais o modo como tanto a literatura quanto os sertanejos reificam uma espécie de vaqueiro simbólico ou representativo ${ }^{15}$ que dá sentido à história nacional (para o saber oficial) e também à tradição sertaneja ou à história de Floresta (para o saber local).

De saída, é preciso deixar claro que não quero com o termo simbólico remeter a uma noção de "estrutura simbólica" que vem a se distinguir como terceiro termo de uma relação entre o "imaginário" e seu oposto, o "real" - tal como o fez o estruturalismo, segundo a visão de Deleuze (1974 [1972]: 307). Na verdade, simbólico está no nível da representação apenas provisoriamente. A sua própria representatividade se esgota - como haverei de mostrar no fim deste artigo - quando vamos em direção a outras formulações, a novos problemas. O que há de representativo no vaqueiro simbólico tem algo de generalizador na medida em que meus interlocutores universalizam determinada verdade histórica. Dessa maneira, o simbólico só é analiticamente produtivo se quisermos compreender os "processos de reificação" (Herzfeld 2008 [1997]) que os sertanejos e a literatura oficial fazem do passado.

Para avançarmos na análise dessa distinção, vejamos as imagens abaixo:

15 Usarei o termo "simbólico" para fazer referência ao vaqueiro nordestino reificado pela literatura, principalmente quando esta vai debater o papel dele na pecuária colonial, mas também para fazer referência ao vaqueiro verdadeiro reificado pelo saber local. No entanto, usarei o termo segundo os sentidos conceituais dados por Lalande (1967 [1927]) em seu dicionário filosófico. Para o autor, "simbólico" se refere ao uso de símbolos ou àquilo que constitui e fabrica um símbolo representativo de algo, de algum objeto, por exemplo (idem 939). Neste caso, "ser o símbolo de uma coisa" ou "representar com um símbolo alguma coisa" (idem 940) é mais ou menos o modo como a reificação dos interlocutores tem relações diretas com a imagem estanque ou referencial do vaqueiro como parte de uma história, de um passado, de uma tradição. 


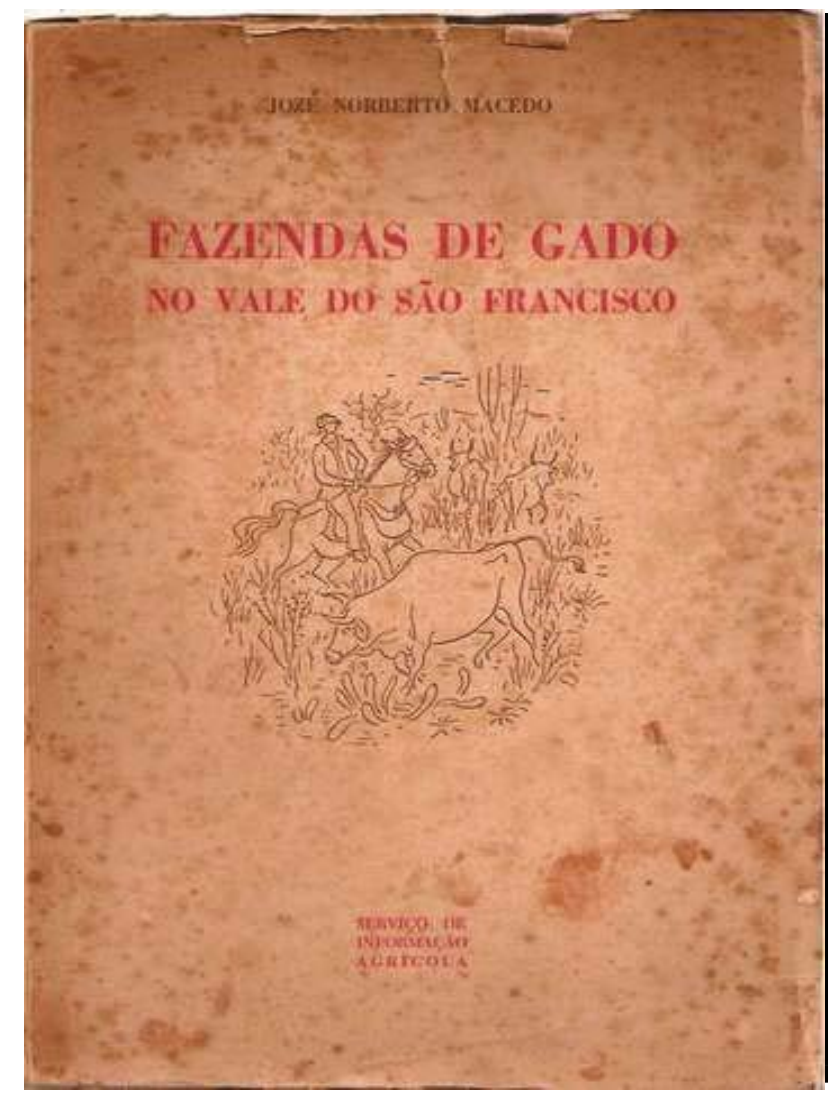

Imagem 01. Capa que demonstra a relação inextrincável do cavaleiro com o boi.



Imagem 02. Vaqueiro do artigo lido por Nilda Ferraz.

A imagem à esquerda é a capa de um livro de José Norberto Macedo (1952) que, como o título mesmo já indica, fala das fazendas de gado no Vale do São Francisco. A outra, ao lado direito, é o vaqueiro do Nordeste representado no artigo do livro que Nilda Ferraz, como demonstrei na seção anterior, utilizou para me asseverar que o homem ali representado era o vaqueiro de verdade. Na primeira imagem, é interessante notar que, ao tratar-se da pecuária nordestina (tema abrangente que envolve uma série de questões, personagens e contextos), a representação imediata para a capa do livro seja exatamente a do cavaleiro que, na caatinga, lida com o gado selvagem - tal a importância desse recorte imagético para estancar a história de fazendas, boiadeiros e vaqueiros. Na imagem à direta, mais uma vez, é o próprio: o vaqueiro tradicional, original e autêntico que Nilda Ferraz concluiu ser um dos símbolos de sua tradição.

Os próprios vaqueiros, ao falarem do passado, da tradição e do tempo dos antigos, traziam em suas narrativas uma série de valores históricos, econômicos e morais que definiam a vida de vaqueiro do passado como algo único, simbólico, remetendo-se a um modo de vida do qual sentem saudade. Segundo diziam, dificilmente a vida de vaqueiro se realizaria hoje com a glória de outrora. Suas lembranças os tornavam tão saudosistas quanto o próprio folclorista Câmara Cascudo que, em sua obra de 1956, Tradiçôes Populares da Pecuária Nordestina, nos dá a seguinte ideia: 
Apesar de tudo, a fazenda é o mundo fiel ao seu passado. Não se revela imediatamente a uma pergunta de repórter para a revista ilustrada. Existe tempo para a intimidade, para a confiança, para a confidência. Depois fica-se sabendo que aquele é mundo encantado e bem diferente do pensamento inicial. Os animais, as árvores velhas, os caminhos, os recantos, o recorte dos serrotes têm histórias, explicações etiológicas, fabulário, crônica. Há uma multidão de heróis que jamais darão à História a honra de uma visita. Vaqueiros de outrora, carreiros admiráveis, rastejadores infalíveis, aboiadores de voz mágica, feiticeiros maiores que Merlino, amores, dedicações, sacrifícios, raptos, valentias, gente bonita, enamorada e boa, tudo morto, mas presente e ressuscitando nas vozes evocadoras e doces, vivem realmente e participam da existência funcional presente. Daria livro, mas há o pudor religioso de não obrigar aquele mundo a entrar para o bojo da garrafa de Salomão, nem achatá-lo numa página infiel às luzes e cores realmente possuídas. (Cascudo 1956: 16).

Se, nas palavras do autor, os sertanejos se renovariam sendo fiéis à história, reproduzindo-a e mantendo-a intacta a despeito das transformaçóes, outros autores sustentaram a prerrogativa de que os costumes e os valores concernentes à lide pastoril não iriam sobreviver com o processo de modernização (Prado Jr. 2006 [1945]), por diversas razões: a introjeção sistematizada do capitalismo, a instauração de novas tecnologias produtivas, as divisas e a Lei de Terras de 1850 (que instituiu a propriedade privada no Brasil), os cercamentos e os limites dividindo os campos outrora compartilhados etc. A modernização resultaria na imediata perda do protagonismo do vaqueiro nordestino como sujeito econômico, ou então, o vaqueiro se tornaria recalcitrante e reprodutor de seus velhos costumes e crenças, encerrado na esfera social retrógrada em que vive (Prado Junior 2006 [1945]; Ribeiro 1995; Mello 2011 [1985]).

Ora, é nesse sentido que a literatura e o saber oficial apresentam os seus próprios limites para o entendimento da noção nativa de tradição, justamente porque sua iniciativa é a de congelar os coletivos, os indivíduos e as relações sociais em tipologias pretéritas, e, além disso, de enquadrá-los em modelos, sem antes prestar a devida atenção ao que se atualiza, refaz-se e muitas vezes escapa aos próprios enquadramentos analíticos. Ao desconsiderar por completo as atividades por meio das quais os vaqueiros se atualizam e resistem, o saber oficial relega ao passado a singularidade histórica do vaqueiro e passa, simultaneamente, a interpretar o presente como mera reprodução social.

Em contrapartida, os vaqueiros entre os quais realizei pesquisa de campo diziam que o mundo da fazenda é um contexto muito distinto do que já foi um dia. Para eles, o passado não se fideliza no presente. Aliás, o tempo pretérito, a tradição e a memória são na verdade pontos de partida para avaliar quem é ou não é vaqueiro, quem o foi de fato ou quem ainda o será. A esse respeito, apresentarei na seção seguinte algumas reflexões com o intuito de avançar a proposta aqui pretendida: demonstrar a eficiência da verdade histórica e da tradição do vaqueiro, tentando entendê-las como pontos de diferenciação e de atualização. Para isso, antes é preciso analisar historicamente como os vaqueiros se diferenciavam entre si e de seus patróes. 


\section{Vaqueiros e fazendeiros}

Outra possível generalização do saber oficial é a ideia de que sempre houve uma relação de confiança, de lealdade e de reciprocidade entre fazendeiro e vaqueiro (Cascudo 1956: 27-28; Mello 2011 [1985]: 50). De um lado, o vaqueiro como o trabalhador estimado no qual o patrão deve confiar. De outro, o fazendeiro a quem o vaqueiro deveria respeitar, por lhe distribuir, como moeda de troca, prestígio político e parcela de seu rebanho. Nessa lógica, o fazendeiro foi sempre visto como o elemento dominante da relação. Nas palavras de Euclides da Cunha (1927 [1902]), os vaqueiros estariam sujeitos a uma "servidão inconsciente".

Por sua vez, contrário a essa prerrogativa, o trabalho de Joana Medrado (2012), intitulado Terra de Vaqueiros, dedica-se com exclusividade à análise histórica das relações entre vaqueiros e fazendeiros (em seu caso, na comarca de Jeremoabo, sertão da Bahia), indo além da estagnação do vaqueiro como subserviente aos domínios políticos regionais. A autora parte da hipótese de que mais do que lealdade, confiança e dominação, os vaqueiros detinham os seus próprios meios de resistência, de manutenção e de recriação do "prestígio" e de sua "cultura política" (2012: 36). Em geral, a autora demonstra a partir do significado do vaqueiro como figura leal e obediente que a literatura clássica sempre lhe rogou uma “imagem positiva”, romântica e saudosista (idem 126-127).

Também em Floresta aparece essa “imagem positiva associada ao vaqueiro”. Por meio das inúmeras qualidades morais concentradas em uma única figura, a interlocutora Nilda Ferraz, por exemplo, referenciava os autênticos e originais vaqueiros do passado como os reais sujeitos de sua tradição. Nomeando-os às vezes como personagem e dando-lhes certa positividade histórica, os meus interlocutores extraíam reflexões e asserções sobre quem era ou não vaqueiro à medida que cristalizavam, como simbólico e representativo, os sujeitos do passado - imagem pungente em suas memórias ao lembrarem do tempo em que existia muito gado brabo nas fazendas de seus antepassados, familiares e amigos.

Nesse sentido, para os sertanejos entre os quais realizei pesquisa, a imagem histórica do vaqueiro serve para pensar a posição do outro e refletir sobre si mesmos e o próprio passado. Inclusive, a imagem simbólica do vaqueiro é um artifício estratégico para pensar a história local (a de Floresta e a de suas famílias) e a história nacional (na forma de tradição e de cultura), assim como para criar certas virtudes a respeito da singularidade de seus costumes (enquanto sertanejos ou vaqueiros de verdade), além de conferir positividade a determinados valores e personagens históricos (o vaqueiro simbólico como o antigo homem do campo, sujeito corajoso, honrado e leal).

A singularidade do vaqueiro (que imediatamente remete ao seu desbravamento e à sua liberdade de ação pelos campos indivisos) é o elemento que o conecta diretamente ao passado, à tradição e, portanto, à verdade histórica, mas também ao presente, à sua contemporaneidade. Se o vaqueiro é sempre o sujeito que tem coragem e agilidade para capturar uma rês bravia no campo, tal atitude ainda hoje é a que mais o diferencia de toda a sorte de pessoas que se dizem vaqueiros, mas nunca cumpriram as funções um dia necessárias. O gosto pelo passado reformula o que é o vaqueiro hoje e o que exatamente ele não é mais. A ideia de um vaqueiro simbólico (que busquei construir com a ajuda da literatura e do saber local) serve no mínimo de medida avaliativa e de matriz purificadora que, a partir de um gra- 
diente qualificativo e conceitual, faz os interlocutores desta etnografia botarem em níveis distintos de importância os tipos de vaqueiros existentes em sua realidade.

Assim, é possível defender neste artigo a ideia de que, tanto para a literatura quanto para os sertanejos, tanto para o saber oficial quanto para o saber local, é possível investir certas qualidades, reflexões, temporalidades e características que fazem do vaqueiro do Nordeste uma singularidade histórica. Embora se possa vê-lo sob diversas formas, o verdadeiro vaqueiro será sempre o homem do campo que um dia exerceu funções e teceu sentimentos referentes a outra temporalidade. O vaqueiro simbólico da história nacional, ligado ao que convencionei chamar aqui de verdade histórica, é, portanto, sui generis, e a sua autenticidade resulta das "estratégias de essencialização" que meus interlocutores conduzem por meio de uma "poética social" (Herzfeld 2005 [1997]). Segundo este autor, a "poética social” é um método de análise das contradições sociais e de seus efeitos subsequentes diante da formalização estatal que, como um equalizador das variabilidades repercutidas no seio da "intimidade cultural", volta-se sempre à construção de "essencialismos" e de verdades na vida cotidiana (idem 54).

Embora as reflexões do saber oficial e do saber local estejam contornadas de generalizações e de impressões, às vezes de cunho naturalista e culturalista (Barroso 1930 [1912]; Cascudo 1956; Mello 2011 [1985]), foram elas próprias que notaram a prevalência dos vaqueiros como sujeitos históricos únicos, disputando entre si a posição de ser vaqueiro e buscando ascensão e prestígio sociais. É justamente nesse sentido que, para Medrado (2012), por exemplo, o vaqueiro foi uma espécie de "bilíngue" que transitava por diversos meios e situações. Tecendo árduas críticas às perspectivas clássicas que caricaturaram o vaqueiro nordestino como incondicionalmente "leal" e "fiel" ao dono da fazenda, a autora notou que mais do que reprodutores de valores e de costumes (e obedientes a uma totalidade social) os vaqueiros no seio de suas relações com chefes e terceiros buscavam a todo instante obter prestígio e flexibilizar a sua própria posição.

Um dos principais traços a distingui-lo, tanto no seio da classe dominante quanto entre os trabalhadores em geral, era a capacidade que ele demonstrava de transitar livremente entre o mundo do dono da fazenda e aquele dos trabalhadores, tornando-se "bilíngue" experiente na arte de decodificar normas de comportamento por vezes opostas. Por isso mesmo, o vaqueiro-administrador atuava como porta-voz dos interesses de um ou de outro grupo. No entanto, essa condição de "bilíngue", longe de amortecer o conflito entre as classes, como o termo pode sugerir, fazia do vaqueiro alguém que tinha mais elasticidade e noção do funcionamento social e que podia aproveitar as frestas de comunicação em proveito próprio (Medrado 2012: 127-128)

Desse ponto de vista, os vaqueiros historicamente foram uma massa de trabalhadores da qual eles próprios buscavam muitas vezes se destacar, não só porque lhes delegavam poder político, mas porque exerciam funções variadas e circulavam por diversos meios. Ao analisar processos civis e criminais da comarca de Jeremoabo, entre o período de 1880 a 1900, a historiadora se deparou com várias categorias de vaqueiro, descobrindo-se na dificuldade de unificar o vaqueiro em uma única categoria analítica, a saber: "vaqueiro-administrador", "vaqueiro-procurador", "vaqueiro-inspetor de quarteirão" e "vaqueiro-guarda de tropa" (Medrado 2012: 90-91). 
Há igualmente neste caso etnográfico a impossibilidade de comprimir em uma única definição e imagem todas as características, valores e atributos dos vaqueiros entre os quais realizei pesquisa de campo (vaqueiros de verdade, vaqueiros de vaquejada, vaqueiros de pega de boi, vaqueiros de festa, vaqueirinho, vaqueiros antigos, vaqueiros velhos). Por esse motivo, a fórmula do vaqueiro simbólico, tal como mobilizada pelo saber oficial e pelo saber local, em especial na terceira seção deste artigo, demonstra agora o seu próprio limite analítico. Apesar de o vaqueiro ainda ser passível de generalizações analíticas, por outro lado, como veremos na seção seguinte, o vaqueiro não depende apenas de si mesmo e de suas relações históricas com o outro, mas também de suas relações históricas com os animais e as caatingas.

\section{Modulação ecológica: rebanho, seca e cerca}

Como vimos, em face de seu protagonismo econômico, histórico e político, a literatura notou que o vaqueiro é o reflexo da sociedade sertaneja. No entanto, de modo mais específico, ela assim o interpretou como um "mito de origem" associado à "inegável [...] vitalidade histórica” que, segundo Medrado (2012), "contribuiu muito para a propagação de uma imagem positiva associada ao vaqueiro" (2012: 127), um mito de origem formulado pelas táticas do saber oficial que concentram nele quase toda a totalidade da cultura pastoril. Mas suas táticas fizeram também o processo inverso. Viu na pastorícia o surgimento da própria singularidade humana, como se na figura do vaqueiro estivessem refletidas de uma só vez várias das virtudes do homem sertanejo.

Para Darcy Ribeiro (1995), em O povo brasileiro, a economia pastoril, por exemplo,

conformou também um tipo particular de população com uma subcultura própria, a sertaneja, marcada por sua especialização ao pastoreio, por sua dispersão espacial e por traços característicos identificáveis no modo de vida na organização da família, na estruturação do poder, na vestimenta típica, nos folguedos estacionais, na dieta, na culinária, na visão de mundo e numa religiosidade propensa ao messianismo (Ribeiro 1995: 338)

É nesse sentido que meus interlocutores de pesquisa me disseram algo parecido com as conclusões de Darcy Ribeiro: os vaqueiros e a economia pastoril foram a gênese de uma formação histórica. Mais do que isso, vaqueiros e bois constituíram conjuntamente uma única e só realidade. Ao longo do tempo, os vaqueiros aprenderam e aprimoraram a função de laborar com o gado, estabeleceram com o animal uma relação específica e, a partir disso, fundaram um modo de vida particular, o da pastorícia. Engajando-se em seu trabalho e evoluindo com ele, os vaqueiros investiam suas energias em certa modulação ecológica (antigamente caracterizada pelo uso comum das terras e pela natureza bravia do animal bovino) e superavam de diversas formas a obrigação com o patrão e os costumes básicos.

Como demonstrado na segunda seção, para o vaqueiro Antônio Balbino 'os vaqueiros de antigamente eram uns homi bruto, um índio, um caboclo brabo". Importante observar nessa fala que, além da manifestação bruta do animal bovino, o vaqueiro em sua origem também foi bruto, um homi bruto. Vale notar igualmente que brabo e bruto, neste caso, aparecem como sinônimos um do outro. Frequentemente, o termo brabo se refere ao animal bravio, pouco ou nada domesticado, feroz, selvagem, portanto, bruto. Caso diferente do gado manso, ao qual se investe outros afetos e práticas, como o 
carinho. Os bois e vacas tidos como mansos são seres plenamente domesticados. Já o gado brabo é sempre aquele que se caça (no sentido de capturá-lo e descobri-lo em meio à caatinga) ou que se apropria para demarcá-lo com ferro e sinal para simbolizá-lo como propriedade de alguém, que pertence a uma localidade, a uma fazenda, com o intuito de que os outros não o roubem. ${ }^{16}$ Por fim, vale notar que, para destacar a ferocidade de um boi ou de uma vaca, poucas vezes se utiliza o termo brabo. Diz-se com mais especificidade que a rês é valente, qualidade de animais que, além de bruto ou brabo (porque criado solto e, portanto, bicho que nunca via gente), enfrentam o vaqueiro, desafiam-no e exigem dele a coragem. São animais que não apenas fogem, mas brigam e lutam contra os humanos - tratei disso noutros lugares (Pereira 2016; 2017).

Ora, na percepção de Antônio Balbino, portanto, não só o gado era bruto, como o próprio vaqueiro também o era. A partir de seu esforço mnemônico, percebe-se o surgimento de uma instância máxima de passado, diretamente conectada a um ponto indeterminado no tempo, porém o mais longínquo possível. Uma espécie de exegese que, segundo Benjamin, "não se preocupa com o encadeamento exato de fatos determinados, mas com a maneira de sua inserção no fluxo insondável das coisas" (1985 [1936]): 209). Neste caso, trata-se de um recorte temporal abstrato, capaz de indicar que boi e homem estiveram sempre lado a lado, igualáveis em termos de brutalidade e braveza. A autenticidade do vaqueiro sendo o resultado imediato de sua natureza primeira, e a singularidade histórica da relação entre vaqueiro e boi, uma verdade última (estagnada na imagem do vaqueiro de verdade), talvez porque - agora emprestando aqui as palavras de Soares - no sistema da pecuária nordestina "era o gado que criava o homem ao invés do homem criar o gado" (1968: 38). Contudo, pretendo avançar essa conclusão do autor.

$\mathrm{Na}$ fala de Antônio Balbino, vaqueiro e boi criaram-se um a partir do outro, mutuamente. Os vaqueiros se transformaram em outra coisa a partir do que puderam aprender com os animais. É dessa outra coisa em que se transformaram que os vaqueiros de hoje se espelham e são ao mesmo tempo julgados por outrem, porque dela se aproximam e ao mesmo tempo se diferenciam. Em sua instância máxima de passado, os vaqueiros deixaram de ser o que eram para se tornarem algo que hoje corrobora justamente a seleção de alguns poucos vaqueiros, vaqueiro mesmos. Segundo os mais velhos, os vaqueiros de hoje não valorizam a mesma perspectiva do passado, porque não sabem como era viver no tempo em que 'o bicho era bruto e não via gente'. No tempo em que 'o bicho era criado solto no mato'.

Assim, há uma concepção genealógica de que boi e vaqueiro estão engajados desde os primórdios, uma verdade histórica flexionada pela singularização de um encontro interespecífico posteriormente modificado pelos cercamentos e pela delimitação das terras, por uma nova modulação ecológica que repaginou no sertão do Nordeste os campos por onde transitavam homens e animais. Uma transformação ecológica capaz de modificar inclusive não só a natureza dos animais, mas também a dos humanos.

16 Ao ato de inscrever nas orelhas dos animais (caprinos, ovinos e bovinos) o sinal de seu proprietário (na orelha direita) e o sinal da propriedade (na orelha esquerda), este último chamado de mourão, dá-se o nome de assinar. Ferrar, por sua vez, é demarcar com ferro o símbolo da propriedade e do proprietário no corpo da rês, às vezes também no gado equino. No lombo direito de um boi ou de uma vaca, queima-se oferro que denomina a pessoa do proprietário, normalmente com as iniciais do nome, e, no lombo esquerdo, queima-se oferro que constitui o carimbo de sua propriedade, geralmente um símbolo indicador do nome da fazenda. Sobre a importância dos sinais e ferros na vida rural sertaneja: cf. Barroso (1930 [1912]:185-191) e Medrado (2012: 95); sobre sinais e ferros também na mesma região no que tange à questão da família e do parentesco: cf. Marques (2002: 142; 268) e Villela (2004: 224-225). 
No século XX, segundo Cascudo (1956),

veio, decorrentemente, o cercado de arame, a cerca divisória, mudando ou dando à psicologia sertaneja outro matiz. Quando o vaqueiro conhecia os limites de sua jurisdição pelas divisas quase inexistentes, travessões que a caatinga cobrira, lugares onde um pau-d'arco existira, agora deparava a fronteira fechada com aqueles fios eriçados e hostis. E as cancelas, as porteiras de passagem, multiplicaram-se. Antigamente, ia-se num livre galope, léguas e léguas, numa ilusão de terra comum, indominada e virgem de posse. $\mathrm{O}$ arame deu ao vaqueiro, pela primeira vez, a impressão dominadora da posse alheia, a imagem do limite" (Cascudo 1956: 13).

Contudo, os cercados por si só não bastam. Outro fator transformativo são as secas. À época da minha pesquisa de campo, em 2016, os meus interlocutores falavam especialmente da seca contemporânea que desde pelo menos os anos de 2011-12 afeta, ainda hoje, o sertão pernambucano. Juntos, cercados e secas, segundo eles, foram capazes de transformar historicamente a vida de vaqueiro noutra coisa que não a verdadeira vida no campo e de transformar a natureza do rebanho em outra coisa que não a do gado brabo. Juntos, as secas e os cercados foram dois elementos centrais para justificar a dificuldade de reproduzir, manter, zelar e criar o rebanho.

Em suma, o sistema de divisão de terras e os cercados domesticaram o animal, doravante mais perto e mais preso. Ademais, por conta das estiagens, o gado deixou ser o objeto central de investimento. Da perspectiva dos sertanejos, o boi vem perdendo o seu protagonismo não só como resultado de uma configuração espacial, mas porque é inviável mantê-lo vivo nas secas, tendo que modificar completamente a lida na fazenda e a vida cotidiana no campo. Sendo assim, a mutualidade entre boi e homem sistematizada no passado parece ressurgir mais como falta do que presença, mais como nostalgia do que verdade empírica.

Analiticamente, isso significa que os homens que na austeridade da seca atual lutam para manter seu rebanho vivo, dedicam-se à atividade de pegar o pouco de gado brabo existente e, aliás, não se envergonham em se dizerem vaqueiros diante do outro, provam por si mesmos, pela sua história e pelo seu estilo de vida que a sua posição é resultado de relações concretas com o passado: de um dia ter estado no lugar certo e no tempo certo. Na medida do possível, exercer as atividades que singularizam a vida no campo acaba, portanto, reforçando ainda mais a verdade histórica do vaqueiro do Nordeste, pois são justamente esses homens que, ao se dizerem vaqueiros, dificilmente serão contrariados ou postos à prova publicamente de que eles não os são. Dentro de uma série de elementos avaliativos mobilizados pelos meus interlocutores de pesquisa, constata-se o seguinte: é justamente por meio da estabilização imagética do passado que a verdade do vaqueiro vem à tona. E é com ela que, em geral, eles qualificam alguém como mais vaqueiro do que outros, principalmente quando se trata de um vaqueiro que exerce as atividades que devem ser exercidas e quando se diz ter vivido em um contexto que lhe atribui autenticidade (trabalhando com o gado na fazenda e/ou pegando gado brabo no mato).

Portanto, mais uma vez, viver e se dedicar na medida do possível à vida no campo não é apenas reproduzir um tipo de vida datado que ainda hoje resistiria às intempéries e às transformações sociais, tal como querem a literatura clássica e o saber oficial. Para o caso aqui analisado, trata-se em contrapartida de preservar não só um modo de vida, mas o próprio desejo de ser vaqueiro, de pensá-lo da forma 
como sempre foi e da forma como ainda é possível conduzi-lo a partir de suas relaçóes com os outros, mas também de suas relações com os animais e caatinga.

Mesmo diante das transformações ocorridas no sistema pastoril sertanejo, a essencialização de um tipo de vida que não se pode mais exercer - tal como um dia se fez - é o ponto de conexão do universo do vaqueiro com a sua verdade histórica. Isto é, as constantes inflexões retóricas que servem para fixar uns e não outros na posição de vaqueiro ou que servem para diminuir a posição de uns em relação à de outros (a partir de um gradiente qualificativo e conceitual) trazem nesta análise a fórmula de uma "nostalgia estrutural" que, não por acaso, vem a ser um dos fios de ligação das pessoas com a verdade (Herzfeld 2005 [1997]).

Especificar o que é ser vaqueiro é, portanto, medir o seu lugar e o do outro na autenticidade, na originalidade e na tradição. É estabilizar um modo de vida que diversas vezes aparece como a mais pura e verdadeira. Todavia, tentar encontrar esse modo vida puro e verdadeiro, isto é, tentar encontrar os vaqueiros de verdade (pelo menos da forma como me descreveram Nilda e Quirino na segunda seção deste artigo), levou-me de imediato a pessoas que viviam na cidade com outros empregos (que não o de vaqueiro) e vivendo de outras maneiras (que não a da vida no campo). Aspectos que, por incrível que pareçam, não os retiravam da posição de ser vaqueiro de verdade por morarem na cidade e por não mais exercerem a profissão de vaqueiro. Por seu turno, os vaqueiros véios atestavam a todo instante o seu prestígio de verdadeiro vaqueiro, mostrando-me entre outros coisas que a sua vida já foi um dia muito distinta da que é hoje. Mostrando-me que o passado e a memória por eles mobilizadas são a prova de que são, de fato e de direito, vaqueiros, vaqueiros mesmo.

\section{Conclusão}

Ora, se a história e o modo como a literatura e o saber oficial tratou as transformações sociais do pastoreio importam na análise elaborada neste artigo, elas só são importantes no limite de suas próprias descrições, uma vez que os próprios vaqueiros e o saber local esgotam as problematizações do saber oficial ao demonstrarem que, embora seus modos de existência sejam muitos distintos dos tempos de outrora, os vaqueiros continuam existindo sob novas relações, reinventando-se e recriando o regime da lida da fazenda, da vida de vaqueiro e da vida no campo. Existir como vaqueiro e ao mesmo tempo se distinguir de seus contemporâneos (que se dizem vaqueiros, mas só frequentam vaquejadas, pegas de boi e festejos, por exemplo) provam e atestam ao outro não o que eles próprios são, mas o que foi historicamente o vaqueiro nordestino, o que ele ainda é, o que ele significa e quais os diversos modos de caracterizá-lo ao longo do tempo.

Se muitos tiveram a clareza de definir o que significa ser vaqueiro baseando-se, por exemplo, em livros e em fundamentos teóricos sobre a cultura sertaneja e a tradição, outros, no entanto (por sua vez, os vaqueiros da lida), demonstraram o que significa ser vaqueiro com base no que é hoje possível investir e reelaborar na vida de vaqueiro mesmo sob a modulação ecológica das secas e dos cercados. Dessa forma, tem-se o seguinte quadro geral: uns nos guiando à compreensão do que é o vaqueiro da 
perspectiva da tradição, outros, os próprios vaqueiros, demonstrando a nós o que a literatura não é capaz de explicar.

Afinal, o que significa ser vaqueiro no tempo presente? E, mais ainda, embora já se tenha suposto o seu fim há bastante tempo, por que o vaqueiro não desapareceu? Da perspectiva de meus interlocutores, o passado não é somente um recorte histórico prévio e imutável. Além de certas maneiras de qualificar, diferenciar e identificar a si mesmo no tempo, a história do vaqueiro do Nordeste depende de um conjunto complexo de estratégias contemporâneas de reconstrução dos acontecimentos, através principalmente da memória e da habilidade retórica de conferirem verdade ao que viveram.

Renan Martins Pereira é Mestre em Antropologia pelo PPGAS/UFSCar e doutorando na mesma instituição. É pesquisador do Grupo Hybris (Grupo de Estudo e Pesquisa sobre Relaçôes de poder, conflitos e socialidades), da USP e UFSCar. Bolsista Capes.

\section{REFERÊNCIAS BIBLIOGRÁFICAS}

ABU-LUGHOD, Lila. 1991. "Writing Against Culture”. In: R. G. Fox (org.). Recapturing Anthropology: working in the present. Santa Fe: School of American Research Press.

AIRES, Francisco J. F. 2008. O espetáculo do cabro-macho: um estudo sobre os vaqueiros nas vaquejadas do Rio Grande do Norte. Dissertação de Mestrado, PPGAS/ UFRN, Natal - RN.

ANDRADE, Manoel Correia de. 1986 [1963]. A Terra e o Homem do Nordeste. $5^{\circ}$ ed. São Paulo: Ed. Atlas.

BARROSO, Gustavo. 1956 [1912]. Terra de Sol: Natureza e Costumes do Norte. Rio de Janeiro: Francisco Alves.

BENJAMIN, Walter. 1985 [1936]. “O narrador: considerações sobre a obra de Nikolai Leskov”. In: W. Benjamin. Obras escolhidas. Magia e técnica, arte e politica. São Paulo: Brasiliense, $3^{\circ} \mathrm{ed}$.

CARSTEN, Janet (org.). 2013. Blood will out: essays on liquid transfers and flows. Chichester: WileyBlackwell.

CASCUDO, Luís da Câmara. 1956. Tradiçôes populares da pecuária nordestina. Rio de Janeiro: Serviço de Informação Agrícola. 2005 [1939]. Vaqueiros e Cantadores - Folclore poético do sertão do Ceará, Paraíba, Rio Grande do Norte e Pernambuco. São Paulo: Edusp.

CUNHA, Euclides. 1927 [1902]. Os Sertões (10ª ed.). Rio de Janeiro: Livraria Francisco Alvez.

DELEUZE, Gilles. 1974 [1972]. “Em que se pode reconhecer o estruturalismo?”. In: François Châtelet (org.). História da Filosofia, vol. 8, O Século XX. Rio de Janeiro: Ed. Zahar.

FURTADO, Celso. 2007 [1959]. Formação Econômica do Brasil. São Paulo: Companhia das Letras.

GEERTZ, Clifford. 1978 [1973]. A interpretação das culturas. Rio de Janeiro: Zahar. 

1997 [1983]. O saber local: novos ensaios em antropologia interpretativa. Petrópolis, RJ:

Vozes.

HARAWAY, Donna. 1995 [1988]. "Saberes localizados: a questão da ciência para o feminismo e o privilégio da perspectiva parcial”. Cadernos Pagu 5: 07-41.

HERZFELD, Michael. [1997] 2008. Intimidade Cultural: poética social no Estado-Nação. Lisboa: Edições 70.

IBGE. 1956. Tipos e Aspectos do Brasil (Excertos da "Revista Brasileira de Geografia"). Rio de Janeiro: Ministério da Fazenda.

LALANDE, André. 1967 [1927]. Vocabulario Técnico y Crítico de la Filosofía. Buenos Aires: El Ateneo.

LOPES, Camilo Antônio Silva. 2016. Vaqueiros, seleiros, carreiros e trançadores: uma etnografia com coisas, pessoas e signos. Tese de doutorado. Campinas, SP: PPGCS/Unicamp,

MACEDO, José Norberto. 1952. Fazendas de gado no Vale do São Francisco. Rio de Janeiro: Ministério da Agricultura.

MARQUES, Ana Claudia. 2013. "Founders, ancestors and enemies. Memory, family, time and space in the Pernambuco Sertão". JRAI 19 (4): 716-733.

.2002. Intrigas e Questões: vingança de familia e tramas sociais no sertão de Pernambuco.

Rio de Janeiro: Relume-Dumará: UFRJ, Núcleo de Antropologia da Política.

; VILLELA, Jorge L. M. 2016. “Le Sang et la Politique. La production de la famille dans les joutes electorales au sertão de Pernambouc, Brésil”. Anthropologica 58: 291-301.

MEDRADO, Joana. 2012. Terra de Vaqueiros: relações de trabalho e cultura politica no sertão da Babia, 1880 - 1900. Campinas, SP: Editora da Unicamp.

MENEZES, Djacir. 1970 [1937]. O Outro Nordeste. Rio de Janeiro: Artenova.

MELLO, Frederico P. de. 2011 [1985]. Guerreiros do Sol: violência e banditismo no Nordeste Brasileiro. São Paulo: A Girafa.

PEREIRA, Renan Martins. 2016. "Dominação e Confiança: vaqueiros e animais nas pegas de boi do sertão de Pernambuco". Teoria e Cultura 11: 63-80.

.2017. Rastros e Memórias: etnografia dos vaqueiros do sertão (Floresta, PE). Dissertação de Mestrado. São Carlos-SP: PPGAS-UFSCar.

PRADO JUNIOR, Caio. 2006 [1945]. História Econômica do Brasil. São Paulo: Brasiliense.

RIBEIRO, Darcy. 1995. O povo brasileiro. A formação e o sentido do Brasil. São Paulo: Companhia das Letras.

SANJURJO, Liliana. 2013. Sangue, Identidade e Verdade: memórias sobre o passado ditatorial argentino. Tese de Doutorado. Campinas-SP: PPGAS-Unicamp.

SOARES, Renan Monteiro. 1968. Aspectos sociológicos da pecuária nordestina. Recife, Imprensa Universitária - UFPE.

VILLELA, Jorge Mattar. 2004. O povo em armas: violência e politica no sertão de Pernambuco. Rio de Janeiro: Relume Dumará. 


\section{CAVALEIROS EM TEMPOS DE GLÓRIA: UMA ANÁLISE ETNOGRÁFICA DA HISTÓRIA DO VAQUEIRO DO NORDESTE}

Resumo: Neste artigo, desenvolvo algumas questões abordadas na minha dissertação de mestrado sobre os vaqueiros do município de Floresta, sertão de Itaparica - PE. A partir delas, pretendo analisar como os meus interlocutores se deparam frequentemente com um dilema. Em Floresta, muitos de seus habitantes avaliam e questionam o futuro de vaqueiros de verdade - cavaleiros hábeis na arte de capturar o gado selvagem na caatinga -, ao passo em que imagens, discursos e práticas de vaqueiros de hoje ganham força e vitalidade em missas, festas e vaquejadas, onde são celebrados o prestígio de homens do passado, os seus maiores feitos e suas memórias, contribuindo aliás para novas possibilidades de ser vaqueiro. Por essa razão, examino como as narrativas locais e a literatura nacional constroem uma estabilização imagética e conceitual do passado, articulando temporalidades e espacialidades em que o vaqueiro nordestino se expressa de maneira simultaneamente histórica e contemporânea.

Palavras-chave: Memória; Sertão; Vaqueiro; História; Pernambuco.

\section{HORSEMEN IN TIMES OF GLORY: AN ETHNOGRAPHIC ANALYSIS OF THE HIS- TORY OF THE BRAZILIAN NORTHEAST COWBOY}

Abstract: In this article, I develop some of the issues addressed in my Master 's thesis about the cowboys of the municipality of Floresta, sertão of Itaparica - PE. I intend to analyze how my interlocutors are often faced with a dilemma. In Floresta, many of its inhabitants evaluate and question the future of true cowboys - horsemen skilled in capturing wild cattle in the caatinga vegetation -, at the same time as images, speeches and practices of today's cowboys gain strength and vitality at religious celebrations, parties and vaquejadas, where the prestige of the ancients, their greatest deeds and their memories are celebrated, contributing by the way to new possibilities of being a cowboy. For this reason, I examine how local narratives and national literature construct an imaginary and conceptual stabilization of the past, articulating temporalities and spatialities in which the cowboys of Brazilian Northeastern expresses itself both historically and contemporaneously

Keywords: Memory; Sertão; Cowboy; History; Pernambuco.

RECEBIDO: $20 / 09 / 2019$

APROVADO: $02 / 02 / 2020$ 